NBER WORKING PAPER SERIES

\title{
SUPPLY AND EFFECTS OF SPECIALTY CROP INSURANCE
}

\author{
Ethan Ligon \\ Working Paper 16709 \\ http://www.nber.org/papers/w16709 \\ NATIONAL BUREAU OF ECONOMIC RESEARCH \\ 1050 Massachusetts Avenue \\ Cambridge, MA 02138 \\ January 2011
}

This research was supported in part by the National Research Initiative of the Cooperative State Research, Education and Extension Service, USDA, Grant CA-B*-AEC-7424-CG, and in part by funding from the Giannini Foundation of Agricultural Economics. Alana LeMarchand provided excellent research assistance, particularly in the preparation of the dataset. My thanks also to Ron Lundine of USDA/RMA for his help in understanding the process by which new crop insurance programs are created. The views expressed herein are those of the author and do not necessarily reflect the views of the National Bureau of Economic Research.

NBER working papers are circulated for discussion and comment purposes. They have not been peerreviewed or been subject to the review by the NBER Board of Directors that accompanies official NBER publications.

(C) 2011 by Ethan Ligon. All rights reserved. Short sections of text, not to exceed two paragraphs, may be quoted without explicit permission provided that full credit, including $@$ notice, is given to the source. 
Supply and Effects of Specialty Crop Insurance

Ethan Ligon

NBER Working Paper No. 16709

January 2011

JEL No. D2,Q12

\begin{abstract}
$\underline{\text { ABSTRACT }}$
The federal government has developed a large number of programs to insure various "specialty crops" over the last two decades; a given program is peculiar to a particular county and crop. This development has been particularly notable in California, because of its size and the diversity of crops produced there.

If the extension of federal crop insurance programs to cover fruit and vegetable production has affected either producer or consumer welfare, then we would expect to see this reflected in output and prices. Exploiting variation in the timing of program introduction in different locations for different crops to estimate the effect of crop insurance on the output and prices of the insured crops.

We nd that the supply of and demand for insurance for tree crops is much larger than for non-tree crops. Crop insurance has a small but signicant negative effect on prices of insured crops. This last nding is consistent with the view that demand for such highly disaggregated commodities is likely to be highly elastic. A consequence is that crop insurance for these specialty crops has little benefit for consumers, even when it generates a large supply response.
\end{abstract}

\title{
Ethan Ligon
}

Dept. of Agricultural and Resource Econ.

University of California, Berkeley

Berkeley, CA 94720-3310

ligon@berkeley.edu 


\title{
SUPPLY AND EFFECTS OF SPECIALTY CROP INSURANCE
}

\author{
ETHAN LIGON
}

\begin{abstract}
The federal government has developed a large number of programs to insure various "specialty crops" over the last two decades; a given program is peculiar to a particular county and crop. This development has been particularly notable in California, because of its size and the diversity of crops produced there.

If the extension of federal crop insurance programs to cover fruit and vegetable production has affected either producer or consumer welfare, then we would expect to see this reflected in output and prices. Exploiting variation in the timing of program introduction in different locations for different crops to estimate the effect of crop insurance on the output and prices of the insured crops.

We find that the supply of and demand for insurance for tree crops is much larger than for non-tree crops. Crop insurance has a small but significant negative effect on prices of insured crops. This last finding is consistent with the view that demand for such highly disaggregated commodities is likely to be highly elastic. A consequence is that crop insurance for these specialty crops has little benefit for consumers, even when it generates a large supply response.
\end{abstract}

\section{INTRODUCTION}

The Federal Government has played a role in providing crop insurance to producers of particular sorts of crops across the United States since 1938, soon after Franklin Delanor Roosevelt announced the creation of an institution to provide such insurance. FDR's rationale for

Agricultural \& Resource Economics, University of California, Berkeley and Member, Giannini Foundation of Agricultural ECONOMICS

Date: January 12, $2011 \quad$ Printed January 12, 2011.

This research was supported in part by the National Research Initiative of the Cooperative State Research, Education and Extension Service, USDA, Grant CA-B*-AEC-7424-CG, and in part by funding from the Giannini Foundation of Agricultural Economics. Alana LeMarchand provided excellent research assistance, particularly in the preparation of the dataset. My thanks also to Ron Lundine of USDA/RMA for his help in understanding the process by which new crop insurance programs are created. 
the program had explicitly to do with smoothing supply, as "... neither producers nor consumers are benefited by wide fluctuations in either prices or supplies of farm products." 1

The original system Roosevelt proposed was for wheat, and allowed payment of both premia and indemnities in either cash or in kind, at least in part because in-kind payments by farmers could be used to establish buffer stocks of wheat. What became the Federal Crop Insurance Corporation (FCIC) no longer accepts or makes in-kind payments, and the federal government no longer makes any effort to reduce variation in prices by managing buffer-stocks of wheat or other commodities. It seems that the original motivation for the program - to smooth food supply and prices - has changed. The motivation now has to do with providing an orderly way to improve producer welfare by providing payments to producers in states of nature when either yields or prices are low.

It's been possible to purchase policies to cover low yields of wheat in many states since Federal crop insurance began in 1938. However, both the areas and the crops for which policies are available have expanded over time. Insurance to cover low yields of "program" crops other than wheat emerged in many states in the years subsequent to 1938, and expanded beyond the program crops the the passage of the 1980 "Federal Crop Insurance Act". Only since the late nineties, however, have policies become available for insuring against losses associated with the production of most fruits and vegetables. The number and variety of such products have expanded dramatically over the last decade, following legislative changes made in 1994, 1996 and 2000 designed to encourage the use of crop insurance by farmers.

To grasp the scale of the change, consider just the case of California, where a predominance of fruit and vegetable crops are grown. A given insurance product is specific to a particular crop and county of production. Figure 1 shows both the number of county-crops in a given year according to NASS, and the number of county-crop insurance products offered. From the figure, one can see that in 1981 there were just a handful of contracts offered (28; for almonds, citrus, grapes, raisins and processing tomatoes). There was a sharp increase in 1989, to nearly 500 products, and then an explosion in 1990, followed by an even larger explosion in 1995. The number of products has grown since, and now amounts to about 2300 products across California's 58 counties.

There are two types of justifications typically offered for the provision of crop insurance. The first has to do with concern for producers'

\footnotetext{
${ }^{1}$ New York Times, Feb. 191937.
} 


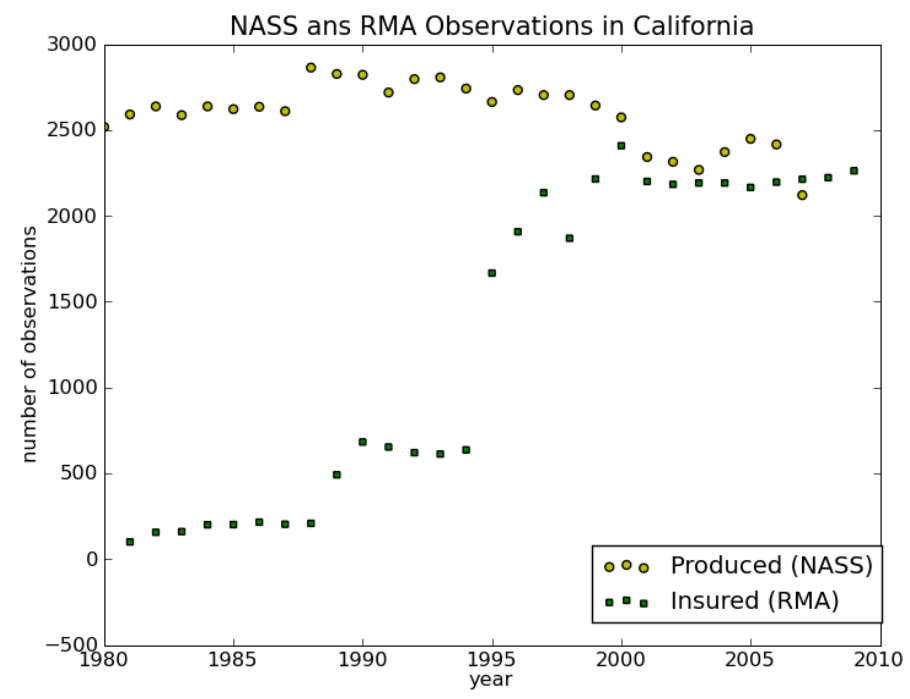

Figure 1. Number of County-Crop Observations and Freqency of County-Crop Insurance Contracts, by Year.

welfare. This is not a trivial concern, especially for fruits and vegetables, since these commodities may involve much more risk than do cereal crops. The second has to do with consumer welfare - the idea is that by providing insurance to a risk-averse producer one can induce those individual producers to act as though they were more nearly risk-neutral, and more willing to make production and management decisions consonant with the interests of consumers. Further, such programs could be expected to encourage entry by new producers, as it lowers the costs to production by risk-averse producers, and thus lower prices.

Specialty crops, particularly fruits and vegetables, differ in several important respects from traditional commodity crops in ways which may affect both demand for insurance and the difficulty of supplying insurance. Let us first consider some demand-side issues. First, prices for many perishable fruits and vegetables have much greater variation than do prices for storable commodities. One might expect this to create increased demand for crop insurance which could deal with this price risk. However, second, a predominance of fruits and vegetable crops in California are marketed via vertical contracts with intermediaries, and in many cases these contracts already play an important role in the producer's risk management (Wolf et al., 2001). The existence of these alternative arrangements for managing risk ought to tend to 
reduce demand for federal crop insurance. Third, because production of many specialty crops is concentrated within a relatively small geographical area, spatial (e.g., weather) shocks which affect production in this area will have a much larger effect on aggregate supply than would a similar shock for a commodity with more geographically dispersed production. As a consequence, negative shocks to yield will cause positive shocks to price - it's not even clear that the average producer will be harmed by such production shocks, since the increase in price may easily exceed the decrease in aggregate production. Thus, demand for yield insurance for any commodity with a combination of geographic concentration of production and inelastic short run demand should be expected to be very low.

Turning to the supply side, the sheer diversity of specialty crops both across commodities and across space for a particular commodity makes the design of appropriate insurance products more demanding than it may be for commodity crops. Further, the well-developed organizations which serve, e.g. wheat farmers in other states and which may serve as an important channel for identifying and marketing to relevant producers will be absent for many (though not all) specialty crops. Related, to the extent that designing an insurance product for a particular crop involves some level of fixed costs (e.g., the costs of the five-year feasibility and pilot programs the RMA conducts), then the return to the investment made in these fixed costs may be lower in a state where there are many diverse crops with geographically concentrated production.

If the extension of federal crop insurance programs to cover fruit and vegetable production has affected either producer or consumer welfare, then we would expect to see this reflected in output and prices. We have high frequency (weekly) data available for wholesale prices of a wide range of fruits and vegetables in California and elsewhere in the country. We have monthly production data for many crops by California county. And then finally we have data on the expansion of crop insurance programs across counties, years, and crops.

This paper uses data on crop insurance policies to explore the variation in the timing of their introduction in different locations for different crops. Aside from simply seeking to describe the data, we're interested in using these data to try and understand something about the supply of insurance (the topic of Section 3). In Section 4 we tackle the central question of the paper: what effect does the introduction of crop insurance programs have on output of the insured crops and on prices of those crops? Section 5 concludes. 


\section{Data on Insurance for Specialty Crops in California}

2.1. Data Sources. For the results and discussion of specialty crop insurance in California found in this paper, we rely principally on two different sources of data. First, data on agricultural production and prices collected by the National Agricultural Statistics Service (NASS), which maintains a database of agricultural production and prices since 1980.2 These data include information for produce as well as for livestock and other crops. Second, the Risk Management Agency (RMA) which administers the FCIC insurance policies maintains a database of insurance policies sold for qualifying agricultural products. ${ }^{3}$

Using data from these two sources, we construct a database which matches data on insurance supply and demand with data on production and prices. The unit of observation in the resulting dataset is a countycrop-year: Since the number of California counties hasn't changed over the period 1981-2007 (the period our analysis covers) and the crops NASS has collected data on haven't much changed, we have a balanced dataset of 190 crops over 26 years and 57 counties (only urban San Francisco County is missing). However, as not all crops are grown in every county, the total number of crop-county pairs is 1053, and the total number of crop-county-year observations is 29,485. Because NASS and RMA use slightly different methods of identifying crops, we had to construct a concordance to match up data from these respective sources: details may be found in Appendix A.

\subsection{Brief Descriptive History.}

2.2.1. Crop Insurance in California. Though a program of federal crop insurance began in the United States in 1938, until 1981 the operations of the Federal Crop Insurance Corporation (FCIC) were extremely limited in two ways. First, prior to 1981 the FCIC only insured program commodities such as grains, dairy and oilseeds, and second, crop insurance consisted mainly of free disaster coverage. However, 1980 saw the passage of the Agricultural and Food Act, which was meant to replace free coverage with an experimental "BUYUP" insurance which required participants to pay an insurance premium for coverage, and which was to be made available for a much broader variety of crops (beyond commodity crops).

Demand in California for the insurance products offered in the eighties was weak. Demand everywhere was weak - despite subsidies which made the expected return to insurance policies large and positive for

\footnotetext{
${ }^{2}$ http://www.nass.usda.gov/Statistics_by_State/California/Publications/AgComm/indexcac.asp

${ }^{3} \mathrm{http}: / /$ www.rma.usda.gov/data/sob/scc/
} 


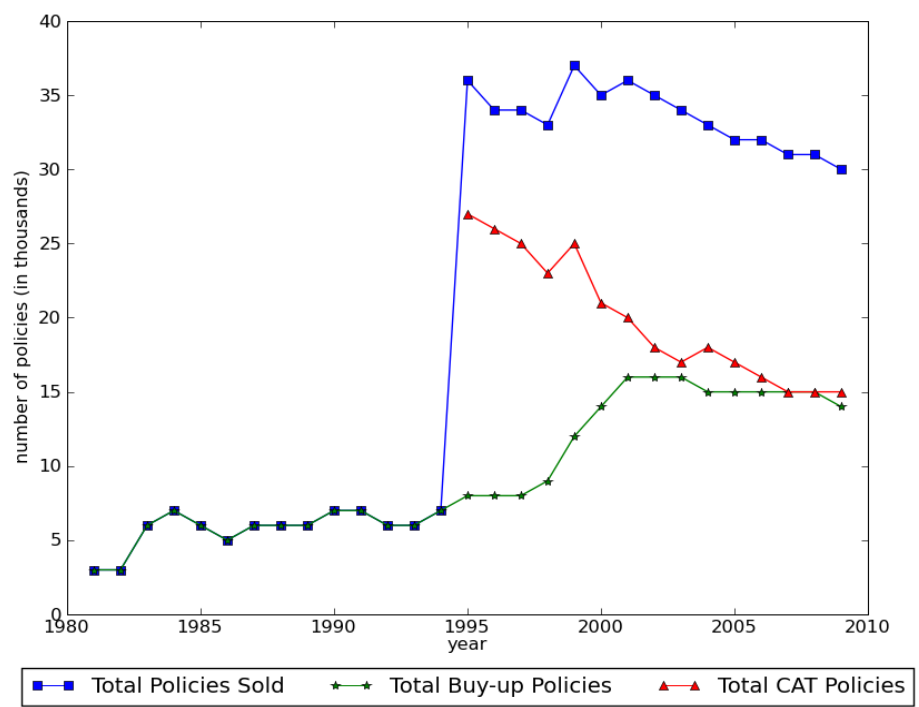

Figure 2. Number of policies sold in California, by category and year.

the average enrolled producer, only 25 percent of eligible acreage was enrolled by 1988 (Glauber, 2004). But because of inadequate data with which to rate policies for specialty crops, insurance products simply didn't exist to cover more than a very small share of agricultural production in California. Figure 3 shows a time series of the number of crops for which policies were offered in California, by year: in 1981 there were only 13 such crops (basically the program crops plus policies for almonds, citrus, grapes, raisins, and tomatoes).

Further, prior to 1985, insurable yields for a particular farm depended on average yields in the county, and adequate data to estimate the distribution of county-level yields even for the small number of insurable crops was limited to a handful of California counties.

After the passage of two ad hoc disaster bills (in 1988 and 1993) (Risk Management Agency, 2009) Congress passed the Federal Crop Insurance Reform Act of 1994 (FCIRA, 1994). The principal goals of the Act were to expand coverage to cover more (especially specialty) crops f $^{4}$ and to increase participation by creating a new category of mandatory.5 Prior to 1994, the insurance policies available offered varied levels of coverage as a function of the premium amount paid. The

\footnotetext{
${ }^{4}$ A list of specialty and nonspecialty crops can be found in Appendix B.

${ }^{5}$ More precisely, having at least CAT insurance became a criterion for producer eligibility for a range of other federal programs.
} 


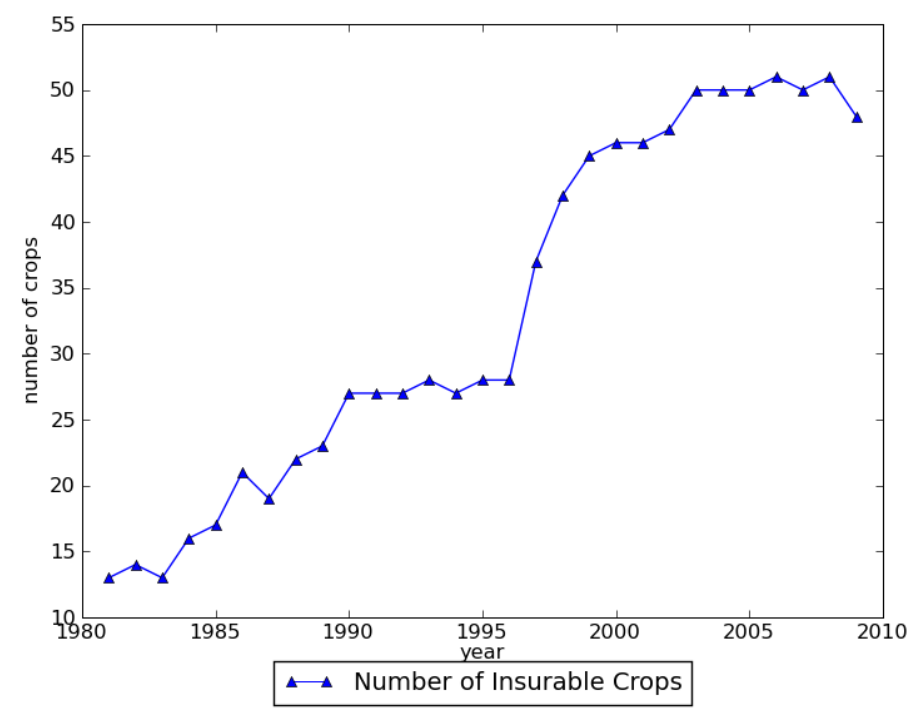

Figure 3. Number of insurable crops in California, by year

catastrophic (CAT) coverage offered in 1994 established a low baseline level of coverag $\AA^{6}$ with no premium (though producers were charged a flat nominal administrative fee). The results of this legislative change for use of crop insurance in California can be seen in Figure 2, In 1995 there was no very large change in demand for the "BUYUP" policies, but a huge increase in demand for the new quasi-mandatory "CAT" policies. This huge increase went a considerable way toward achieving the goal of increasing overall producer participation. However, the increase in participation evident in Figure 2 for California was almost entirely due to the new mandatory CAT insurance - no policy for new California crops was developed by the RMA between 1991 and 1997.7 at which time programs for apricots and nectarines were developed (see Table 1).

A second act of Congress, the Federal Agriculture Improvement and Reform Act of 1996 (FAIR, 1996), gave the option of forgoing CAT insurance, in exchange for forfeiture only of eligibility for Federal disaster

\footnotetext{
${ }^{6}$ Compensation was for "losses exceeding 50 percent of an average yield paid at 60 percent of the price established for the crop for that year".

${ }^{7}$ Of the many specialty crops which aren't covered (in at least some counties), some disaster insurance is available based on county-wide production, rather than on a given producer's production history. These specialty crops are instead covered by the "Noninsured Crop Disaster Assistance Program," which was also created by the 1994 act.
} 


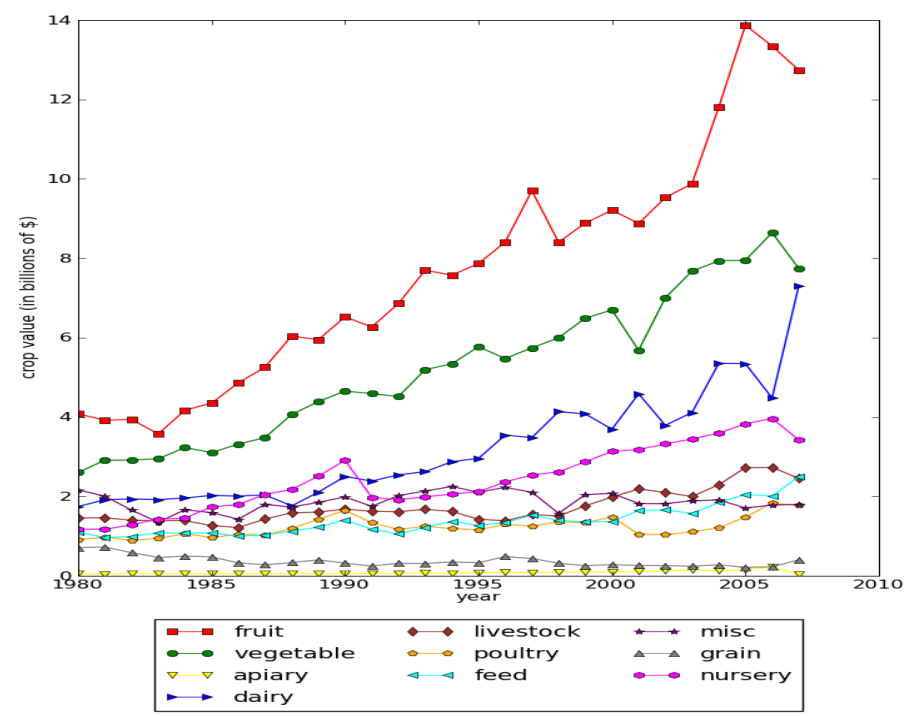

Figure 4. Total market values for California agricultural production

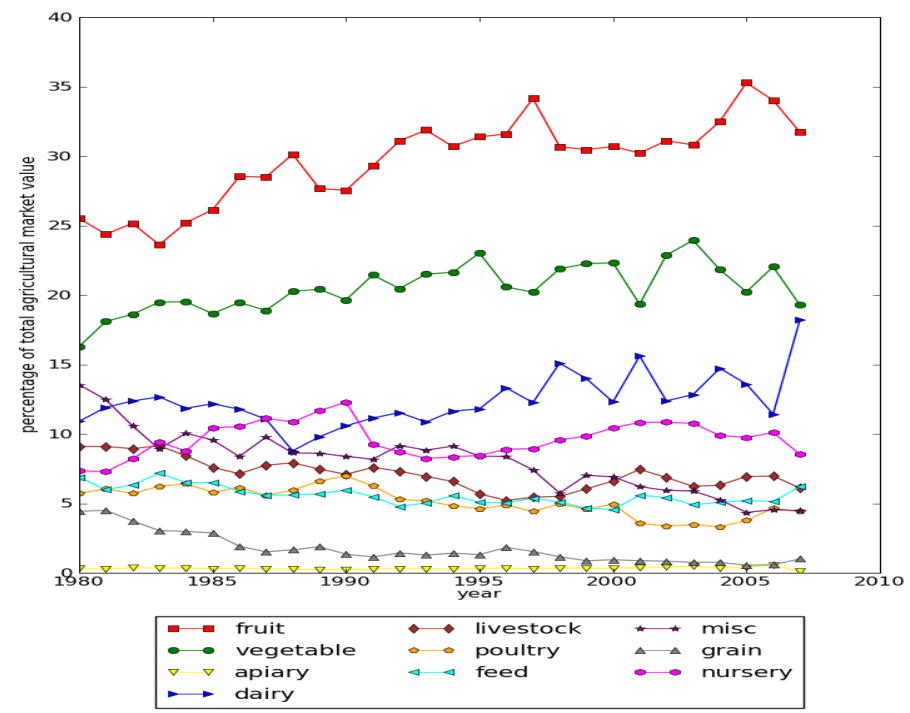

FiguRE 5. Market shares of California agricultural production

benefits. The Act also created the Risk Management Agency (RMA) whose function was to adminster FCIC crop insurance, including researching crops to make insurance available on more crops. 
2.2.2. Notable Features of California Agriculture. Among the important agricultural states, California is notable for the very large share of specialty crops in the total value of its agricultural production. As an examination of Figure 4 makes clear, fruits and vegetables collectively accounted for over half the total value of California agricultural production in 2007, with a collective value of roughly twenty billion dollars. It's not only that the nominal value of fruits and vegetables have been increasing sharply since the 1980s; their share in the total value of California agricultural production has also increased over time, and have exceeded half of total value since about 2000 . The only other class of agricultural commodities to increase its share over this period of time is diary, so between Figure 4 and Figure 5 we see a picture of increasing specialization, with the three highest value categories of agricultural commodities accounting for an increasing share of total production over time.

What accounts for this increased specialization? The increase specialization evident in these figures occurs over the same period in which insurance for specialty crops is introduced. In a study of program crops, O'Donoghue et al. (2009) find that the expansion of crop insurance associated the 1994 FCIRA led to modest increases in on-farm specialization, either because producers substituted toward crops whose expected returns increased with the introduction of subsidized insurance, or because insurance reduced demand for crop-diversification for risk-management reasons. One possibility is that similar mechanisms are at work here, and that with the introduction of insurance the improvement in the (insured) distribution of returns to growing fruits and vegetables led farmers to substitute toward these commodities.

This hypothesis is consistent with Figure 6, which shows not only a steady increase in the total value of Californian agricultural production over time, but also shows that this increase in value is essentially entirely attributable to the increase in the value of insurable crops (i.e., crops produced in a county where insurance is available for that crop). So one might be tempted to infer that the expansion of crop insurance to cover specialty crops over this period led an increase in the value of these crops.

However, this inference is not so straightforward. The problem is that an increasing number of crops became insurable at an increasing number of locations over this period. Furthermore, as discussed below in Section 3, insurance was wasn't randomly assigned to new cropcounties over time; rather, the total value of the crop in a particular location was the key variable which led the RMA to create or expand new programs. So the increase in the value of insurable crops evident 


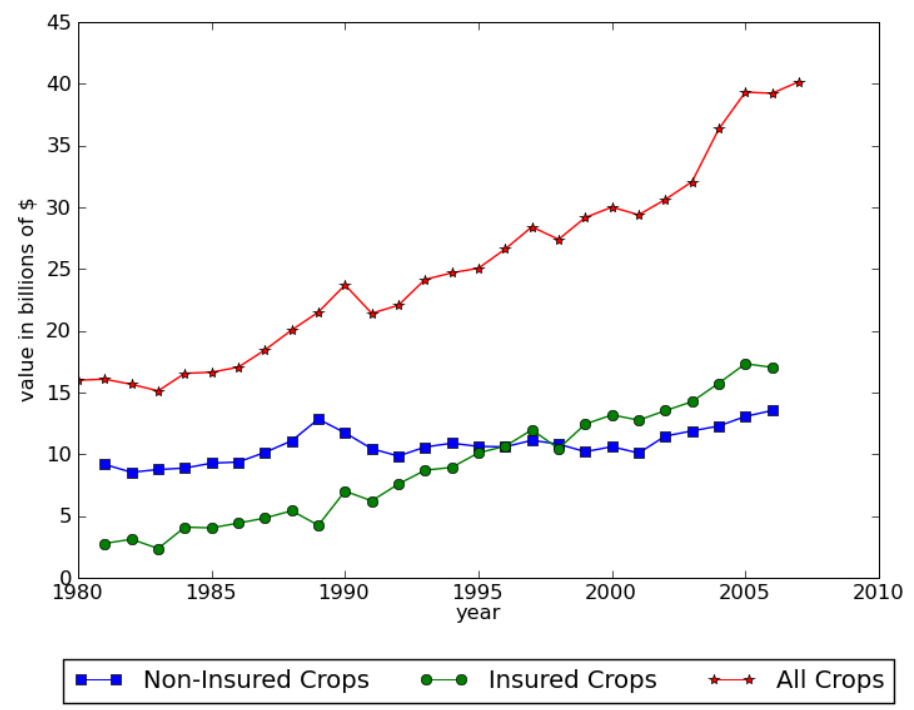

Figure 6. Total market value of California agricultural production

in Figure 6 could easily be entirely a consequence of the way the supply of insurance changed over time, and not have anything to do with either demand for that insurance or with the effects of insurance on crop specialization or production. Sorting out these different possible reasons for the increase in the value of insurable crops is the central goal of this paper.

\section{Supply of Insurance for Specialty Crops in California}

We have data on a total of 190 different agricultural commodities. These are all produced in California, and result from merging of NASS and RMA datasets. Of these 190, the RMA classifies all but 17 as "specialty" crops.

There are 173 fruit and vegetable specialty crops grown in California. Of these, 27 are covered by a crop-specific insurance program in one or more California counties.

Table 1 shows how new insurance policies are offered for different crops at different times. The numbers which appear in each cell indicate the number of California counties (of which there are 58 in total) for which insurance policies are offered for a given crop. So, for example, we see that insurance for walnuts was first offered in 1985, debuted in 10 counties, and by 2007 was offered in 25 counties. 


\begin{tabular}{|c|c|c|c|c|c|c|c|c|c|c|}
\hline $\begin{array}{l}\text { First } \\
\text { In- } \\
\text { sured }\end{array}$ & Crop Name & 81 & 85 & 90 & 94 & 95 & 96 & 97 & 62 & 67 \\
\hline \multirow{5}{*}{1981} & Almonds & 4 & 15 & 16 & 16 & 16 & 16 & 16 & 16 & 16 \\
\hline & Citrus Fruit & 3 & 4 & 8 & 8 & 11 & 12 & 12 & 15 & 15 \\
\hline & Grapes & 8 & 15 & 16 & 17 & 24 & 26 & 26 & 31 & 31 \\
\hline & Raisins & 7 & 7 & 6 & 6 & 6 & 6 & 6 & 6 & 6 \\
\hline & Tomatoes & 6 & 14 & 11 & 11 & 15 & 15 & 15 & 14 & 12 \\
\hline 1982 & Dry beans & & 15 & 15 & 15 & 18 & 16 & 18 & 16 & 3 \\
\hline 1984 & Walnuts & & 10 & 15 & 16 & 25 & 25 & 25 & 24 & 25 \\
\hline 1985 & Potatoes & & 2 & 1 & 3 & 6 & 5 & 5 & 5 & 13 \\
\hline \multirow[t]{2}{*}{1986} & Peaches & & & 11 & 13 & 13 & 13 & 11 & 12 & 11 \\
\hline & Prunes & & & 10 & 11 & 12 & 14 & 14 & 14 & 13 \\
\hline \multirow[t]{2}{*}{1988} & Apples & & & 2 & 1 & 9 & 10 & 12 & 17 & 12 \\
\hline & Figs & & & 3 & 3 & 3 & 3 & 3 & 2 & 2 \\
\hline 1989 & Pears & & & 3 & 4 & 8 & 7 & 7 & 7 & 5 \\
\hline \multirow[t]{3}{*}{1990} & Fresh Mkt & & & 2 & 3 & 6 & 5 & 6 & 5 & 4 \\
\hline & Tomatoes & & & & & & & & & \\
\hline & Fresh Plum & & & 6 & 4 & 7 & 8 & 8 & 7 & 6 \\
\hline \multirow[t]{2}{*}{1997} & Apricots & & & & & & & 11 & 11 & 10 \\
\hline & Nectarines & & & & & & & 7 & 7 & 6 \\
\hline \multirow[t]{2}{*}{1998} & Avocados & & & & & & & & 6 & 5 \\
\hline & $\begin{array}{l}\text { Sweet pota- } \\
\text { toes }\end{array}$ & & & & & & & & 1 & 5 \\
\hline \multirow[t]{2}{*}{1999} & Cherries & & & & & & & & 2 & 2 \\
\hline & Wild rice & & & & & & & & 3 & 3 \\
\hline 2000 & Strawberries & & & & & & & & 2 & 3 \\
\hline 2002 & $\begin{array}{l}\text { Raspberry \& } \\
\text { Blackberry }\end{array}$ & & & & & & & & 1 & \\
\hline \multirow[t]{2}{*}{2003} & Nursery & & & & & & & & & 3 \\
\hline & Onions & & & & & & & & & 1 \\
\hline 2007 & Alfalfa Seed & & & & & & & & & 1 \\
\hline 2008 & Pecans & & & & & & & & & 2 \\
\hline
\end{tabular}

TABLE 1. Number of Counties with Insurance Products for Different Crops. On the left is the first year the crop was introduced; generally policies were sold every year following. Selected years afterward (on the right) are simply a snapshot of subsequent years, including more detail around the 1994 FCIRA and 1996 Farm Bill. Each entry for a year and crop represents only the number of counties in which policies were sold for that year and crop. 
If the decision to offer insurance for a particular crop in a particular region was left to competitive firms, each seeking to earn a profit through the development of new policies, then we'd expect the the supply of insurance to depend on the equilibrium price. However, for crop insurance in the U.S., the decision to offer insurance for a particular crop in a particular county is a bureaucratic one, made not by the insurance firms that sell the product, but rather by the RMA. It's not entirely clear what the objectives of the RMA are, but it does seem clear that maximizing profits from the provision of insurance is not among its principal objectives: the net cost of crop insurance to the U.S. treasury is well in excess of 3.5 billion dollars per year (General Accounting Office, 2007). 8

Regardless of the RMA's objectives in creating new insurance products, we know quite a lot about their decision rule, as they have developed a rather clear procedure for determining whether to offer insurance for a particular specialty crop in a particular region General Accounting Office, 1999, Appendix III).

There are three basic criteria which must all be satisfied for a product to be developed. First, the crop must be "economically significant"; second, there must be "producer interest"; and third, offering the product must be "feasible" (General Accounting Office, 1999, Appendix III).

The FCIC regards a particular crop economically significant in a particular area only if the total market value of the crop is at least one of the following:

(1) $\$ 3$ million in the agricultural statistics district (of which there are nine in California) where it will be covered;

(2) $\$ 9$ million in the state where it will be covered;

(3) $\$ 15$ million in the RMA administrative region (of which there are ten nationwide); or

(4) $\$ 30$ million nationally.

Producer interest in insurance is considered to be indicated by high levels of noninsured disaster payments as well as recommendations by

\footnotetext{
${ }^{8}$ It's possible that the RMA weighs the costs of this subsidy against what the costs of disaster relief would be in absence of crop insurance. In 2002, when insured acreage nationwide was roughly 80 per cent of the total with average coverage of roughly 60 per cent, Congress allocated $\$ 2.1$ billion in supplemental disaster assistance. If in the absence of any crop insurance the Congress allocated enough money to provide similar relief the allocation would then be on the order of $\$ 4.4$ billion. But since disasters of this scale seem to occur less often than every other year, it's not at all clear that ad hoc disaster relief is less cost-effective than are existing crop insurance programs.
} 
RMA regional offices. For a pilot program to be initiated projected producer participation in the program much be at least 10 per cent.

Offering an insurance product may be infeasible if, for example, there are inadequate data to evaluate the actuarial soundness of the product; if mechanisms to market the product are lacking; or if the proposed product itself is too complicated (General Accounting Office, 1999).

Once the RMA has decided to try to develop a new insurance product, the process of development takes about five years to complete. including two years of feasibility studies and three years to carry out a pilot program.

Operationally, the criteria for economic significance described above don't offer sufficient guidance about what crops to develop programs for, as very many crops in many locations satisfy those criterion, and the RMA presumably lacks the resources to develop programs for all of these at once $9^{9}$ To deal with these constraints, the RMA has developed a list of crops ranked according to market value. We understand from conversations with analysts within RMA that this list provides primary guidance about what crop to focus on next, and that the RMA seldom initiates new programs for more than a single crop per year.

\begin{tabular}{r|rrrr}
\hline \hline & \multicolumn{4}{|c}{ Specification } \\
Variable & $(1)$ & $(2)$ & $(3)$ & $(4)$ \\
\hline County Fixed Effects & Yes & Yes & Yes & Yes \\
Crop Fixed Effects & No & Yes & Yes & Yes \\
Year Fixed Effects & No & No & Yes & Yes \\
Value Rank-Year Interactions & No & No & No & Yes \\
\hline Log-likelihood & $-14061.02^{*}$ & $-6627.50^{*}$ & $-4382.37^{*}$ & $-4341.32^{*}$ \\
Degrees of Freedom & 57 & 162 & 24 & 27 \\
\hline \hline
\end{tabular}

TABLE 2. Factors effecting the probability of new crop insurance programs across different counties.

We wish to test the hypothesis that the RMA's decisions regarding what crops to insure in what counties depend on the value of the crop in different counties. Our approach is to model the probability of a policy being offered for a particular crop-county-year. Let $d_{i j t}$ be equal to one if a policy for crop $j$ is offered in county $i$ in year $t$, and equal to zero otherwise.

\footnotetext{
${ }^{9}$ Over the period 1982-2008 there has been on average less than one new California crop program developed per year, and in no year has there been more than two new crop programs introduced.
} 
We imagine that there are characteristics of counties or crops which are essentially fixed in the short run, but which may affect the probability of a crop policy being introduced in that county. Obvious features of counties which could matter include the overall importance of agriculture in that county, or the effectiveness of insurance salespeople operating in that particular area. Features of crops which are fixed and may affect the probability of policy introduction may include features of the commodity itself which may make it infeasible to introduce insurance, or involve commodity-specific grower associations which are more or less enthusiastic about the introduction of insurance policies for their particular crop (a correspondent at the RMA tells us that lettuce growers in California have resisted the introduction of crop insurance).

Let $R_{j t}$ denote the RMA's ranking of the crop value in year $t$ (with the lowest-value crop receiving a ranking of 1 ). We estimate

$$
\operatorname{Prob}\left(d_{i j t}=1\right)=\alpha_{i}+\gamma_{j}+\eta_{t}+\left(\sum_{s=1980}^{t} \delta_{s}\right) R_{j t}+v_{i j t}
$$

where the $\left\{\alpha_{i}\right\}$ are a collection of county fixed effects, the $\left\{\gamma_{j}\right\}$ are a collection of crop fixed effects, and the $\left\{\eta_{t}\right\}$ are a collection of year effects. The term $\left(\sum_{s=1}^{t} \delta_{s}\right) R_{j t}$ allows there to be a time varying but cumulative effect of crop ranking on probability of a policy being offered.

We use a logistic model to estimate (1), with results reported in Table 2. Each successive column adds an additional collection of variables and reports the resulting log-likelihood, so that column (1) for example presents a measure of fit for a regression of policy offerings on just a set of county fixed effects, column two adds crop fixed effects, and so on. The reported log-likelihood ratios allow us to construct likelihood ratio tests of the null hypothesis that the coefficients associated with the newly added variables are all equal to zero.

Each of the collections of county, crop, and year effects jointly are significant, and explain a great deal of variation in whether or not a policy is offered. Though no individual term in the 'rank-year' interactions is statistically significant, these are collectively extremely important in terms of explaining variation. We interpret this as evidence that even after throwing out variation at the level of the county, the crop, and the year that our characterization of the RMA's supply decision is useful in predicting what crop-counties will have insurance products developed for them. 


\section{Effects of Insurance on Output and Prices}

The consequences of crop insurance programs for consumer welfare can be presumed to depend on two different channels: first, the cost of the programs to taxpaying consumers; and second, via the effect the progams have on prices and quantities of agricultural commodities purchased by consumers.

It's reasonably straightforward to document the direct costs of FCIC programs for U.S. taxpayers. From the GAO report cited above (General Accounting Office, 2007), we have a figure of roughly $\$ 3.5$ billion per year, or roughly $\$ 30$ dollars per year for each U.S. household. There are numerous elaborations on these costs available in the literature, and on estimates of the welfare losses involved in having the government involved in effecting these transfers from taxpayers to producers (e.g., Gardner and Kramer, 1986, Wright and Hewitt, 1994, Glauber, 2004).

In comparison, the literature on the ultimate effects of crop insurance on prices and quantities is surprisingly small, and small relative to the literature on demand for crop insurance or its effects on farmer behavior. Young et al. (2001) is an exception: using a computable general equilibrium model they estimate the effects of crop insurance subsidies on prices and supply of eight program crops. They find a small shift (a $0.4 \%$ increase in planted acres) toward production of those crops, but since demand for those same program crops is inelastic prices tend to fall by a much larger proportion. Overall they compute that the roughly $\$ 1.5$ billion dollars spent in crop insurance premium subsidies led to an increase in farm income of roughly one billion dollars.

Here, by exploiting variation in the timing of the introduction of crop insurance policies across crops and counties and then combining this with county-level data on prices and output, we're in a position to try and deliver some tenative estimates of the effects of crop insurance on the observable variables most germane to consume welfare. The findings of O'Donoghue et al. (2009) lead us to expect that the introduction of crop insurance programs will, other things equal, lead to some substitution toward the insured crop and hence produce an increase in output. However, the different crops we examine are highly disaggregated and most have close substitutes or can be grown in other counties, states, or countries. Accordingly, we'd expect demands to be highly elastic. If this is correct, then increased supply will have at most a modest effect on prices.

We begin by considering a simple reduced-form supply relationship, which takes the form

$$
\log q_{i j t}=\alpha_{i}+\gamma_{j}+\eta_{t}+\beta d_{i j t}+\epsilon_{i j t}
$$


where (as before) the $\left\{\alpha_{i}\right\}$ are county-dummies; the $\left\{\gamma_{j}\right\}$ are crop dummies; and the $\left\{\eta_{t}\right\}$ are year dummies. A couple of features of this equation are worthy of note. First, in a supply equation we'd ordinarily expect prices to feature prominently on the right-hand-side of the equation, but prices do not appear explicitly in (2). The reason is that we implicitly assume that prices will vary only across crops, counties, and time, and so any variation in price will be captured by some combination of the dummy variables which appear prominently in $(2)$.

Second, the crop dummies are particularly important here, as they allow us to avoid the problem that the output of different crops are measured in different units. So long as these incommensurate units (e.g., cartons of mature green tomatoes; pounds of almonds) are unchanging over time, the combination of taking logs and adding crop-specific dummies allows us to compare the dimensionless percentage changes output across crops.

However, the key coefficient of interest for us is $\beta$, which captures the effects of introducing crop insurance for a given county-crop on supply. This coefficient can be interpreted as an elasticity - the introduction of insurance for a particular crop in a particular county be expected to increase production by a factor $\beta$.

The problem with estimating (2) as it stands, of course, is that the introduction of crop insurance is endogenous. Indeed, making the point that crop insurance depends importantly on observables such as value rank was the main point of Section 3. However, we can use the results of Section 3 to address the problem of endogeneity here. In particular, if one were to take the estimates the conditional probabilities of a program being introduced for a given crop-county from the estimation reported in Table 2, we could treat this as a sort of 'first stage' in a twostage-least squares estimator of the effects of crop insurance on supply. For this strategy, we would let $\hat{d}_{i j t}$ denote the estimated probability of introduction, and then use these estimates in a 'second stage'

$$
\log q_{i j t}=\alpha_{i}+\gamma_{j}+\eta_{t}+\beta \hat{d}_{i j t}+\epsilon_{i j t} .
$$

In effect, the interactions between rank and years which appear in (1) would act as 'instruments' for the endogenous introduction of crop insurance.

In practice, using a logit-first stage with a least-squares second stage would make inefficient use of the information contained in the first stage right-hand-side variables, and complicate estimation of standard errors. Accordingly, we adopt a GMM or 3SLS approach to estimation. A nice consequence of this approach is that since we have more 
excluded instruments than coefficients to estimate we can also test the specification and validity of our instruments, as well as remaining quite agnostic as regards the covariance structure of residuals ${ }^{10}$

Our estimate of the value of $\beta$ in (2) appears in the first column of Table 3. We find that the introduction of insurance for a given crop has a highly significant effect on the quantity supplied - there's no doubt great variation across commodities in terms of this supply response, but our estimate is that on average there's a 138 percent increase in output for crops with crop insurance, compared with uninsured crops. However, our ability to test the underlying specification is useful here: we're able to reject the hypothesis that our instruments are valid in this specification at a five percent level of confidence.

In a search for the reasons for the rejection it was suggested to us that the effects of crop insurance on supply might differ dramatically between annual and perennial crops, on the logic that sunk costs for perennial crops implied that producers of such crops would have to bear considerably greater risk in the absence of insurance. We explore this idea by introducing an interaction between whether or not a crop was a "tree crop" or not.11

The second column of Table 3 shows the result. In place of an indicator for "Policy available" we interact a pair of indicator variables for tree and non-tree crops with the policy availability indicator; the pair of coefficients associated with these variables then become estimates of the elasticities we seek. And indeed, introducing this heterogeneity of response makes a remarkable difference. For tree-crops the estimated supply elasticity increases somewhat, to 164 percent. But for non-tree crops the estimate (while still positive) is not statistically distinguishable from zero.

The estimated elasticity of 1.64 is not very precisely estimated - a ninety-five percent confidence interval about this estimate is [1.11,2.17]. But even if imprecise, the elasticity tells us that in counties where crop insurance for tree crops was introduced it stimulated a doubling or tripling of production over the 27 years for which we have production data. But note that this should not be interpreted as evidence of an

\footnotetext{
${ }^{10}$ This flexibility does come at a price: with a full set of rank-year interactions the GMM optimal weighting matrix can't be reliably estimated using our finite sample. Accordingly, we use a smaller set of decade-rank interactions as excluded instruments in the estimates presented here.

${ }^{11}$ Not all California crops can be unambiguously identified as annual or perennial, since for some crops this depends on location. However, all tree crops are perennial, and so we've used this as a method of distinguishing effects.
} 
overall increase in output across all crops-2 doesn't allow us to distinguish between increases in total output across crops and substitution between crops. It's entirely possible that the introduction of subsidized insurance actually leads producers to substitute away from higher-value crops (or perhaps lower-value crops better suited to a particular farm), reducing the total value of production 12

We won't pursue the issue of the effects of crop insurance on the total value of agricultural output here, for want of data (our analysis here relies heavily on variation across crops, and so aggregating across these has a high cost in terms of both the statistical power and size of any tests we might conduct). Instead, we'll return to a consideration of the demand side, on the grounds that any positive effect of crop insurance on consumer surplus must come via a reduction in the prices of insured commodities.

Accordingly, we specify an inverse demand function for produce of type $j$ from county $i$ in year $t$ according to

$$
\log p_{i j t}=\alpha_{i}+\gamma_{j}+\eta_{t}+\beta \log q_{i j t}+\epsilon_{i j t} .
$$

There's some abuse of notation here, as we're 're-using' variables which entered the supply equation (2). Hopefully context makes it clear that these are all in fact different quantities. Only the quantity supplied $q_{i j t}$ is common across equations (2) and (4). As in our specification of the supply equation, we have a set of county fixed effects, a set of crop fixed effects, and a set of time effects.

As in (2), the crop dummies $\gamma_{j}$ are critical allowing us to make comparisons of price across crops measured using different units. The time effects play an even more important role here than previously, because they capture changes over time in the value of the dollarwe've left the values of prices $p_{i j t}$ in nominal terms, so that the $\left\{\eta_{t}\right\}$ terms capture the effects of inflation on prices.

In this case, the key variable of interest is quantities - what we'd like to know is how changes in the quantity supplied affect prices. But of course these quantities are endogenous - if we didn't already know this from examination of (2) we could see that we're contending with the

\footnotetext{
${ }^{12} \mathrm{~A}$ casual investigation of this hypothesis involves substituting total crop value for total crop production in (2). This yields estimates suggesting that the introduction of insurance results in an increase in tree-crop value smaller than the increase in tree-crop production, while the value of non-tree crops actually falls significantly in response to the introduction of insurance. However, tests of the overidentifying restrictions result in a rejection of this specification; further investigation is left for future research.
} 


\begin{tabular}{r|rr}
\hline \hline Variable & $(1)$ & $(2)$ \\
\hline Policy Available & $1.38^{*}$ & - \\
& $(0.23)$ & \\
Policy $\times$ Non-tree & - & 0.50 \\
& & $(0.49)$ \\
Policy $\times$ Tree & - & $1.64^{*}$ \\
& & $(0.27)$ \\
\hline Excluded Instruments & $\mathrm{d}$ & $\mathrm{d}$ \\
$\chi^{2}$ & 11.12 & 6.80 \\
$(p$-value $)$ & $(0.05)$ & $(0.13)$ \\
Estimator & GMM & GMM \\
\hline \hline
\end{tabular}

TABle $\overline{\text { 3. Estimated Average Supply Response }}$ to Crop Insurance and the Average of the Reciprocal of Price Elasticity of Demand. For crops grown in California. The top panel presents GMM estimates of coefficients in (2) (county, crop, and year fixed effects are included but not reported). Figures in parentheses are standard errors; asterisks indicate significance at greater than 5 percent level of confidence.

classic problem of separately identifying supply and demand relationships. But our estimation of (2) suggests a strategy to address this endogeneity: by using predicted values of (log) quantities from (2) in place of actual quantities, we obtain

$$
\log p_{i j t}=\alpha_{i}+\gamma_{j}+\eta_{t}+\beta \widehat{\log } q_{i j t}+\epsilon_{i j t} .
$$

Then estimates of the coefficient $\beta$ can be interpreted as the average of the reciprocal of price elasticities (thus values close to zero imply high elasticities). Since this is the only parameter of interest we don't need a table to report it: we estimate an inverse demand elasticity of -0.056 , with a standard error (computed using the heteroskedasticityconsistent method of White (1980) ) of 0.003 . Thus, we find a negative elasticity, consistent with the law of demand, and significantly different from zero. Indeed, our estimate is reasonably precisely estimated - a 95 per cent confidence interval about the estimate is $[-0.050,-0.062]$, suggesting that demand is quite elastic. This is consistent with the hypothesis that such highly-disaggregated commodities are likely to permit a great deal of substitution. As before, recall that this is an average reciprocal elasticity - for commodities which are only grown in 
a few counties in California or which possess no close substitutes price elasticity may be much smaller.

\section{Conclusion}

In this paper we've gathered evidence on the process by which crop insurance programs are created, and used this evidence to estimate the 'supply' of crop insurance programs across counties, crops, and years. We've found that an administrative rule which gives priority to crops with the highest ranking value has considerable predictive power, though crop and county specific variables also play an important role.

We've used our predictions regarding the introduction of crop insurance to deal with issues of the endogeneity of the supply of crop insurance programs and estimate the effects of the introduction of crop insurance programs on both the supply of and demand for different crops.

Our estimates regarding the effects of crop insurance on the supply of and demand for insured crops indicate that effects differ for tree and non-tree crops, perhaps as a consequence of the much larger investments at risk in crops of the former type. We find what we think is a rather large effect on supply for tree-crops, but no significant effect for non-tree crops. However, we can't say whether the large effect of insurance on tree-crop production is principally due to more efficient production or substitution away from other crops.

We find a significant negative effect of crop insurance on prices for insured crops, though the magnitude of the effect is small (around -56 percent). This last finding is consistent with the view that demand for such highly disaggregated commodities is likely to be highly elastic. A consequence is that crop insurance for these specialty crops has little benefit for consumers, even if it generates a large supply response. 


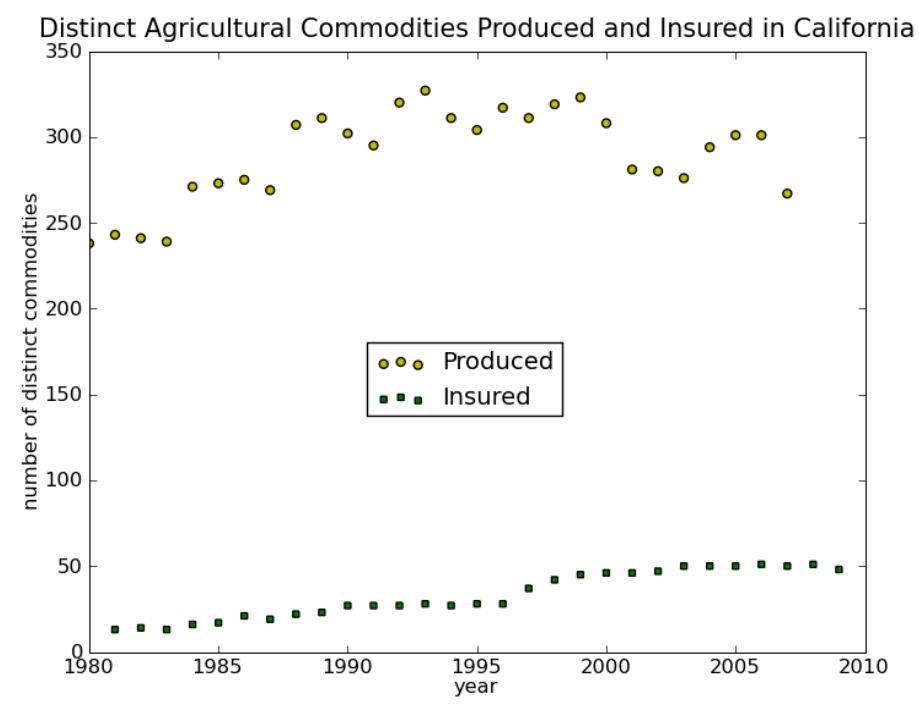

Figure 7. Number of distinct commodities in the California agriculture market, as defined by NASS

\section{Appendix A. Detailed Data Description $\sqrt{13}$}

The production and insurance data obtained from the NASS and RMA websites are organized differently. First, the production data (which date from 1980) use a unique commodity, county and year as the unit of observation, while the insurance data groups data by crop, year, county, and insurance plan. Second, the RMA definitions of crops are less specific (and broader reaching) than the NASS definitions; thus, there are many more production commodities than insurance crops.

A.1. Production. Output information is reported as acres harvested, tons produced, and total market value, as appropriate for the commodity type (animal commodities, for example, only include information for total market value). The number of counties with production data stayed primarily constant year over year, ranging from 57 counties (1980-1988) to 59 counties (2004-2007).

A.1.1. Production Types. The raw data have been further organized by an external classification by broad production type:

(1) fruit

(2) vegetable

\footnotetext{
${ }^{13}$ This appendix was written with Alana LeMarchand. Additional details and discussion may be found in her Berkeley undergraduate honors thesis of 2009 .
} 


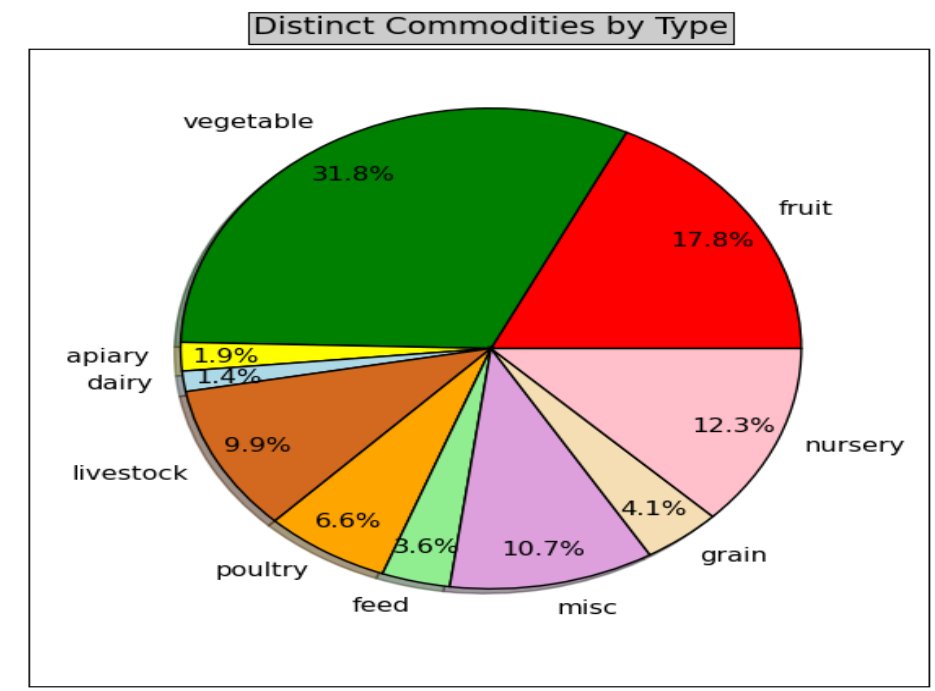

FIGURE 8. Distinct agricultural commodity names in California, as defined by NASS, grouped by type
(3) apiary
(4) dairy
(5) livestock
(6) poultry
(7) feed
(8) misc
(9) grain
(10) nursery

There are many more unique commodities in the fruit and vegetable categories than in the other categories, although this is not necessarily related to the actual aggregate market value of goods of different types. Analysis of the share of actual market value of each production category indicated that the number of commodities in each category is not correlated with market share.

A.2. Insurance. While the insurance data includes such supplementary information as premium and coverage level, the most pertinent information is which commodities are insured and the type of insurance plans offered. The total number of commodities insured since 1989 is 63 but there have never been more than 51 commodities insured in a single year. The number of insured crops began at 23 and increased 
with time, including an abrupt jump in the year 1997 (28 crops in 1996, 37 crops in 1997).

A.2.1. Insurance plan types. There are seven insurance plan types offered. The following description is adapted from material available on the RMA website ${ }^{14}$ including information for less traditional pilot programs.

AGR: Adjusted Gross Revenue: insures revenue of the entire farm rather than an individual crop by guaranteeing a percentage of average gross farm revenue, including a small amount of livestock revenue. The plan uses information from a producer's Schedule F tax forms, and current year expected farm revenue, to calculate policy revenue guarantee

APH: Actual Production History: insure producers against yield losses due to natural causes such as drought, excessive moisture, hail, wind, frost, insects, and disease. The farmer selects the amount of average yield he or she wishes to insure; from 50-75 percent (in some areas to 85 percent). The farmer also selects the percent of the predicted price he or she wants to insure; between 55 and 100 percent of the crop price established annually by RMA. If the harvest is less than the yield insured, the farmer is paid an indemnity based on the difference. Indemnities are calculated by multiplying this difference by the insured percentage of the established price selected when crop insurance was purchased.

ARC: Avocado Revenue Coverage: pilot since 1998

ARH: Actual Revenue History: pilot for dry beans in 2009

CRC: Crop Revenue Covereage: provides revenue protection based on price and yield expectations by paying for losses below the guarantee at the higher of an early-season price or the harvest price

DOL: Dollar Plan: provides protection against declining value due to damage that causes a yield shortfall. Amount of insurance is based on the cost of growing a crop in a specific area. A loss occurs when the annual crop value is less than the amount of insurance. The maximum dollar amount of insurance is stated on the actuarial document. Amount of insurance is based on the cost of growing a crop in a specific area. A loss occurs when the annual crop value is less than the amount of insurance. The

\footnotetext{
$14_{\text {http: //www.rma.usda.gov/policies/ }}$

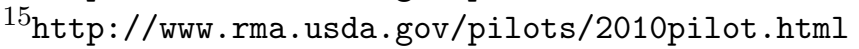


maximum dollar amount of insurance is stated on the actuarial document.

GRP: Group Risk Plan: policies use a county index as the basis for determining a loss. When the county yield for the insured crop, as determined by National Agricultural Statistics Service (NASS), falls below the trigger level chosen by the farmer, an indemnity is paid. Payments are not based on the individual farmer's loss records. Yield levels are available for up to 90 percent of the expected county yield. GRP protection involves less paperwork and costs less than the farm-level coverage described above.

PRV: Pecan Revenue: since 2005, began as a pilot.

\section{A.2.2. Qualitative distribution of plans in the data.}

AGR: Adjusted Gross Revenue: This plan is not crop specific and applies only to the entire production of a farm.

ARH: Actual Revenue History: This plan is sold only beginning in 2009 as a pilot for dry beans.

GRP: Group Risk Plan: This plan is indexed on county production and comprises an insignificant percentage of policies sold.

APH: Actual Production History: This plan is by far the most common plan type and is linked most directly with production volume.

CRC: Crop Revenue Covereage: This plan protects a farmer's crop based on yield and price. It is also more significant in terms of numbers than the AGR, ARH, or GRP plans.

DOL: Dollar Plan: This plan protect against yield shortfall below a certain dollar amount. It is the second most common plan, after the APH.

PRV: Pecan Revenue: This plan applies only to pecans and could only be useful in regressions where policies are linked specifically to crops.

ARC: Avocado Revenue Coverage: This plan applies only to avocados and could only be useful in regressions where policies are linked specifically to crops.

A.2.3. Graphical Presentation of Insurance Plan Distribution. Figure 9 presents data on premia, liabilities, indemnities, and subsidies for each RMA insurance plan category. Raw data is included below each bar chart in . "Premium" and "Net Reported Acres" are scaled so as to be more readable. 


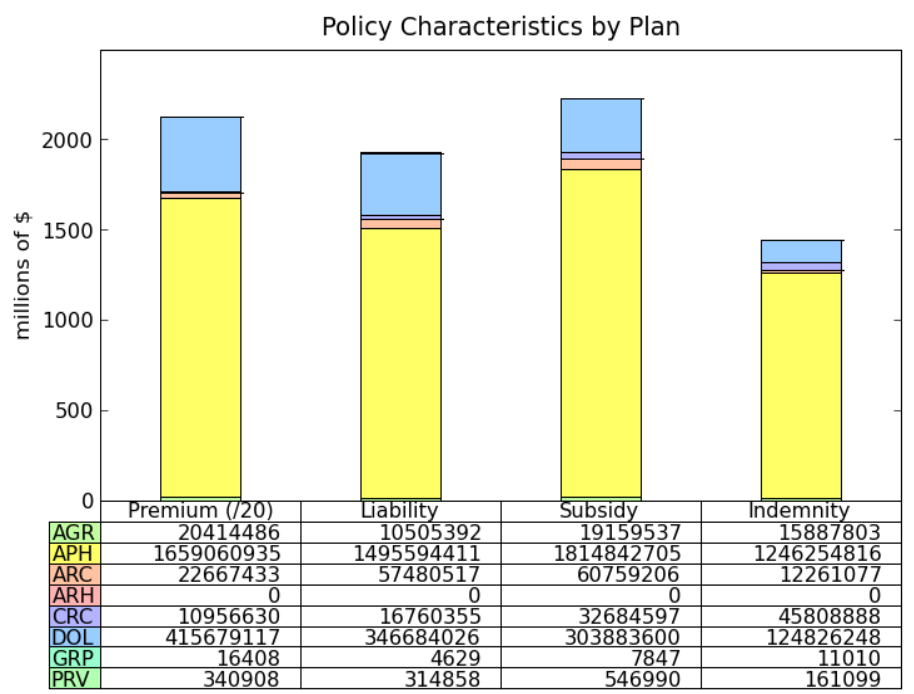

Figure 9. Distribution in California, by RMA insurance plan category, of cumulative monetary value of total premiums, liabilities, subsidies, and indemnities

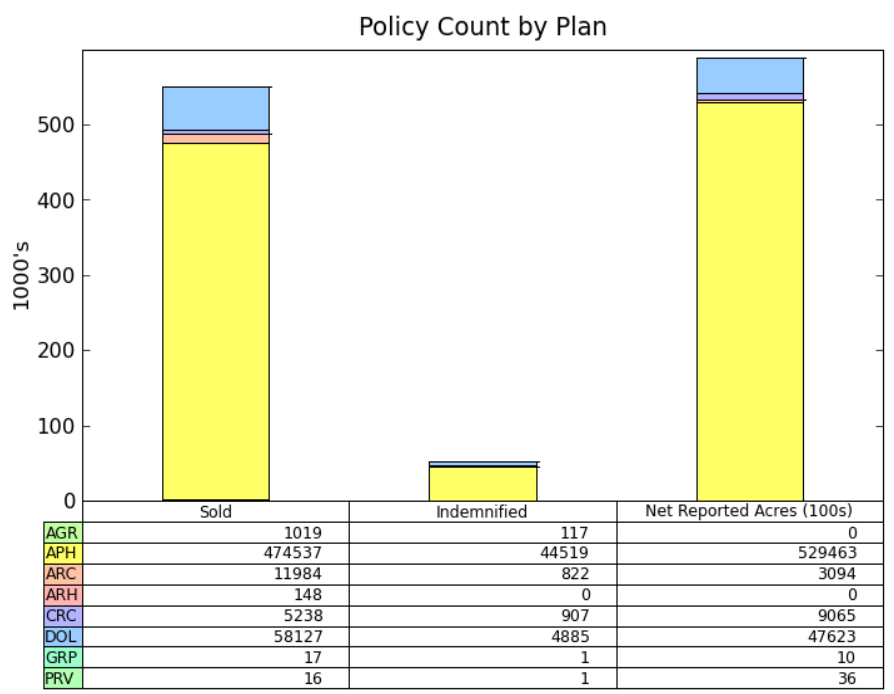

Figure 10. Cumulative number of policies of each category sold in California since 1980 
Figure 10 simply indicates the number of policies offered by plan. It is clear from this data that traditional APH policies comprise the great majority of RMA insurance plan activity, with the DOL plan a very distant second. After that, the most significant share of policies comes from the AGR, ARC, and CRC plans. As mentioned, AGR insurance is not crop specific and thus is inappropriate for a crop specific analysis; ARC insurance is only for avocados; CRC is crop specific and applicable to many different crops. ARH, GRP, and PRV are insignificantly small. However, ARC, ARH, and PRV plans may be included in regressions where policies are linked specifically to crops. They might also be studied later on for their influence on the avocado, dry bean, and pecan markets, respectively.

A.3. Production-Insurance Correspondence. As shown above, there are many more production commodities than there are insurance crops. This due in part to the nature of the insurance crop designation (more general, spanning several production commodities), but also in part to the fact that many crops are not insured. Correspondences between production and information have been established using the crop and commodity names of each respective data set. There are 100 production commodities found to correspond to 56 insurance crops.

All insurance crop designations encompass one or more production commodity designation except in a few fruit crops. Tangelos, plums, and apricots have two insurance crop identities corresponding to a single production comodity (usually due to a distinction between fresh and processing grade fruit).

The other notable aspect of the link created between production and insurance information is that there are 7 commodities which could not as of yet be linked with production commodities. This is due to ambiguous categories definitions (i.e. four types of insurance categories and 6 types of production categories for oranges). These unlinked insurance commodities include: special citrus, processing beans, nursery (container), Adjusted Gross Revenue, stonefruit and oranges.

This correspondence permits the comparison of production of insured crops to production of uninsured crops. Figure 11 shows that mean production value of insured crops is above that of uninsured crops over the entire 30 year period analyzed; overall growth of market value of insured crops is also greater than for uninsured crops (although this may not necessarily be true for percent growth).

Appendix B. List of Specialty and Nonspecialty Crops 


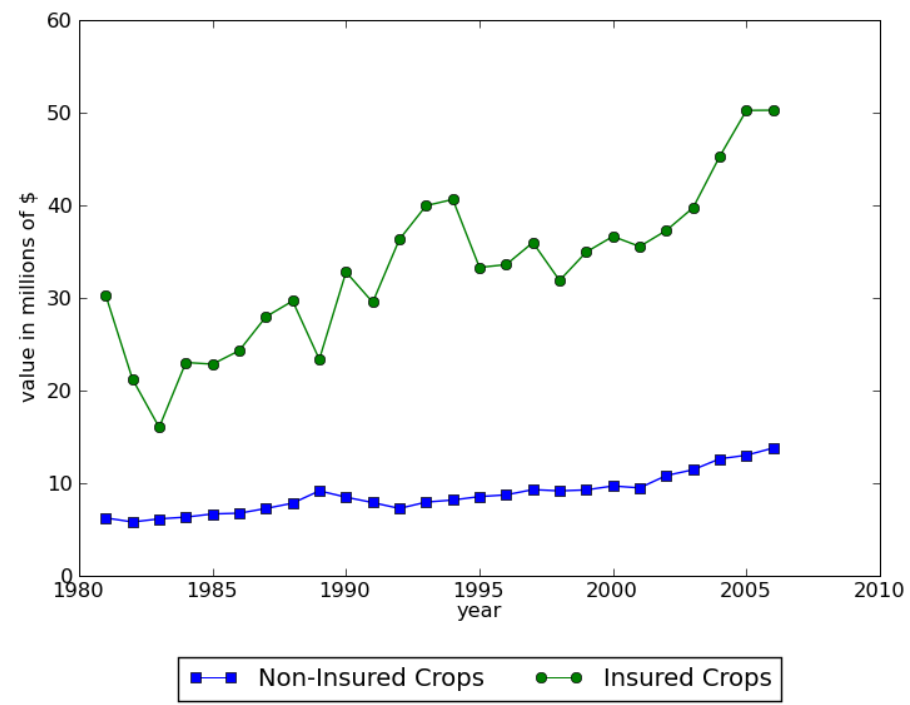

Figure 11. Mean production value (total market value divided by number of crops) for California agricultural production

\section{Specialty Crops}

Almonds

Apples

Avocado/ mango trees

(Florida)

Avocados

Blueberries

Canning beans

Citrus trees

Citrus

Cranberries

Dry beans

Dry peas

Figs

Florida fruit trees

Grapes (table)

Grapes (wine)

Green peas

Macadamia nuts

Macadamia trees

Nursery
Onions

Peaches

Pears

Pecans

Peppers (fresh)

Plums

Popcorn

Potatoes

Prunes

Raisins

Stonefruit

Sweet corn (fresh)

Sweet corn (processing)

Tomatoes (fresh)

Sweet potatoes

Tomatoes (processing)

Walnuts

Non-specialty Crops

Barley

Canola

Corn 
Cotton

Extra long staple cotton

Flaxseed

Forage production

Forage seeding

Grain sorghum

Hybrid corn seed

Millet

Peanuts

Rice
Rye

Oats

Safflower

Soybeans

Sugarbeets

Sugarcane

Sunflowers

Hybrid sorghum seed

Tobacco

Wheat

\section{Appendix C. Integration of RMA Crop Value List ${ }^{16}$}

One such list assembled by the RMA using crop value data from 2005 and 2006 was made available by the RMA correspondent for the above stated research purposes. The list included information on crops at all stages in the insurance policy process, from those at full regulatory status (those already insured) to those not yet being considered for new policies, and eveything in between. However, since the informal list contained data for uninsured crops as well as for insured crops, many crops could not be identified with the unique FCIC crop codes which have been previously used to organize crop information in the research database and to define a correspondence between RMA policy information and NASS production and price information. Indeed, no numeric identifiers were used at all in the list provided. In addition, there were several critical discrepancies and complications which must be resolved before integrating the list information into the database:

- The national crop values reported do not correspond to NASS nationwide reported crop values (only a few were checked, and some were off by $50 \%$, but not by orders of magnitude). Since this the list is significant for this research as an indicator of relative crop value as condsidered by the RMA, this may not be considered significant.

- One third of the listed crops are missing crop value information for 2006. According to the RMA correspondant, the incompletion of some columns can be considered insignificant. In this case it may be preferable to use only the 2005 crop value data in order to generate a relative ranking of crops by value.

- Three of the crops contained not crop value data whatsoever (for either year). These crops were chicory, collard greens, and kale. The latter two crops are grown in California so it remains

\footnotetext{
${ }^{16}$ This section drawn from the thesis of Alana LeMarchand.
} 
to be determined whether these crops should be thrown out of the list or not. For now they will be dropped from the list as insignificant in determining rank by crop value since they comprise less than $2 \%$ of the 163 observations.

- A few high value crops were aggregated in the list. Notably, citrus fruit (all oranges, grapefruit, etc), citrus trees (a pilot in Florida), dry beans (limas, red, navy, etc), and floriculture (all non bulb flowers). To appropriately integrate this data into a new table in the existing database, all crops corresponding to each of these categories would need to have the same ranking (or to be aggregated as a single crop to reflect the RMA's consideration of them as a single crop. This is generally typical of RMA reporting compared to NASS reporting: an RMA policy of a certain general crop name will generally correspond to apply to several NASS commodities. It is important to note, however, that there were crops which were subject to aggregation even among varying RMA crop policies, namely citrus fruit and peaches.

- Several crops in the nationwide list are not grown in California and thus are not present in the current database. Since these crops will not be significant in the research beyond determining a nationwide crop value rank, they will not be tied or added to the current FCIC and NASS crop lists in the database. Their crop code will be marked null in the database, indicating that they are not California crops.

An initial version of the list has been generated using the above modifications. For simplicity's sake, we create a third unique identifier in addition to the NASS and FCIC codes in order to capture the aggregation described above.

Correspondences were simple to make in most cases but the following is a list of crops with problematic correspondences, primarily due to lack of specificity of which NASS crops are represented by these RMA crop names, since the RMA uses different crop nomenclature than the NASS does: 


\begin{tabular}{l|lr}
\hline \hline RMA crop name & NASS names & NASS codes \\
\hline Corn & Corn Grain & 111991 \\
Forage & Pasture Forage Misc & 194799 \\
Forage Seeding & Hay Alfalfa, Hay Green & 181999,195299 \\
& Chop & \\
Hybrid Seed Corn & Corn Seed & 171119 \\
Silage: Corn/Sorghum & Corn Silage, Sorghum 111992, 114992, 195199 \\
Sweet Corn (processing, in- & Silage, Silage \\
stead of fresh) & Not distinct from "fresh" in & NULL \\
Trees & NASS data & \\
\hline \hline
\end{tabular}

The resulting data have been inserted as three tables with the following fields into the database.

\begin{tabular}{rrr}
\hline \hline \multicolumn{3}{c}{ Table Name } \\
rank_ID & rank_list & rank_status \\
\hline ID & ID & codep \\
ins_code & status & name \\
prod_code & value & \\
& name
\end{tabular}

represents the aggregation solution discussed above. The rank_list table may be used to generate crop value rankings (as a temporary auto incremented and indexed table with a MySQL query) based on RMA status, in the event that it would be useful to include or to exclude certain status categories (such as "regulatory," which signifies crops already fully insured).

\section{REFERENCES}

FAIR (1996). Federal Agriculture Improvement and Reform Act, Number P.L. 104-127.

FCIRA (1994). Federal Crop Insurance Reform Act, Number P.L. 103354.

Gardner, B. and R. Kramer (1986). Experience with crop insurance programs in the United States. In P. Hazell, C. Pomareda, and A. Valdes (Eds.), Crop Insurance for Agricultural Development. Baltimore: Johns Hopkins Univ. Press.

General Accounting Office (1999, April). Crop insurance: Usda's progress in expanding insurance for specialty crops. GAO/RCED 99-67, General Accounting Office. Report to the Ranking Minority Member, Subcommittee on Risk Management, Research, and Specialty Crops, Committee on Agriculture, House of Representatives. 
General Accounting Office (2007, May). Crop insurance: Continuing efforts are needed to improve program integrity and ensure program costs are reasonable. GAO 07-819T, General Accounting Office.

Glauber, J. (2004). Crop insurance reconsidered. American Journal of Agricultural Economics 86(5), 1179-1195.

O'Donoghue, E., M. Roberts, and N. Key (2009). Did the federal crop insurance reform act alter farm enterprise diversification? Journal of Agricultural Economics 60(1), 80-104.

Risk Management Agency (2009). A History of the Crop Insurance Program. Risk Management Agency.

White, H. (1980). A heteroskedastic-consistent covariance matrix estimator and a direct test for heteroskedasticity. Econometrica 48 , 817-38.

Wolf, S., B. Hueth, and E. Ligon (2001). Policing mechanisms in agricultural contracts. Rural Sociology 66(3), 359-382.

Wright, B. D. and J. A. Hewitt (1994). All-risk crop insurance: Lessons from theory and experience. In D. L. Hueth and W. H. Furtan (Eds.), Economics of Agricultural Crop Insurance: Theory and Evidence, pp. 73-112. Kluwer Academic Publishers.

Young, C. E., M. L. Vandeveer, and R. D. Schnepf (2001). Production and price impacts of u.s. crop insurance programs. American Journal of Agricultural Economics 83(5), 1196-1203. 